\title{
Shock Wave Interaction with Composite Materials
}

\author{
A. van der Steen
}

TNO Prins Maurits Laboratory, Lange Kleiweg 137, P.O. Box 45, 2280 AA Rijswijk, The Netherlands

\begin{abstract}
A large number of physical and chemical parameters determine the sensitivity of explosives. Special emphasis is placed on the influence of the crystal quality on the initiation process. First the crystal size is considered for monomodal and bimodal distributions. It seems that the Lee-Tarver model is not capable to explain all the experimental observations. Other parameters like the crystal shape, the smoothness of the surface of the crystal, internal defects and dislocations (like voids), and the effect of a binder in a PBX are also discussed. From the experimental results known up to now it is clear that an optimised crystal quality can help to obtain less sensitive explosives. For this the study of the crystallisation process is a key item.
\end{abstract}

\section{INTRODUCTION}

The sensitivity of explosives is like a balance. On one side the explosive has to be as insensitive as possible to enhance the safety and on the other side the functioning of explosives will be negatively effected if the sensitivity is too low. For those reasons sensitivity has always been a topic in the detonation community.

To describe the sensitivity of explosives is very complicated. First of all it is an intrinsic property of the explosive molecule itself. Enormous progress is being made in relating the chemical structure to the sensitivity. While Kamlet related sensitivity to the composition of organic explosives, later Delpuech and Odiot linked the sensitivity to the properties of the excited electronic state of the molecule [1]. In this way a relatively good estimate of the sensitivity of a new molecule can be obtained before it has ever been sensitised.

On a larger scale the physical properties of the crystal lattice play a role in the sensitivity. Coffey and Armstrong for example relate the mechanical properties of the lattice to the impact sensitivity [2]. They assume that a pile-up of phonons will occur on dislocations in the lattice and will act as ignition sites. Many investigators have related the crystal size to the sensitivity. Moulard has shown the importance of the crystal size in relation to the shock sensitivity of PBX's [3]. Spear has investigated the shock sensitivity of RDX as a function of the crystal size [4]. A more theoretical approach is given by the Lee-Tarver model that describes the ignition and pressure build-up during shock initiation assuming spherical particles with one specific diameter.

However, crystals never behave ideally and most of the time the imperfections in the crystals determine physical properties such as the shock sensitivity. Just as for liquid explosives that can be sensitised by air bubbles, the sensitivity of solid explosives depends strongly on the number and type of dislocations and imperfections in the crystal lattice. Mishra was one of the first who showed experimentally that the impact sensitivity of RDX depends on the solvent used for crystallisation [5]. The different solvents resulted in 
different crystal shapes. Also van der Steen et al. have shown the influence of the crystal shape on the shock sensitivity [6]. They have shown that a decrease of the critical initiation pressure of more than $1 \mathrm{GPa}$ can be reached if speroidized crystals with smoothed surfaces are used. Borne has shown that the concentration of voids in RDX crystals effects the sensitivity [7]. The small number of experimental evidence is contrary to the large number of theoretical models describing the creation of hot-spots.

A last but certainly not least important contribution comes from the state in which the explosive is applied. Large single crystals are not used in warheads or boosters. All kinds of different processing techniques are used and processing aids are added to make the explosive applicable: pressing, casting, extruding, mixing (like CompB), addition of waxes or polymers, plasticizers, etc.. Pressed explosives with a minimum of voids between the binder and the explosive have a significantly higher sensitivity than cast-cured explosives. The interaction between the binder and the explosive contributes also to the sensitivity. According to Swallone the mechanical properties of the polymer influence the sensitivity of the PBX [8]. This is also suggested by Shedelbauer [9]. Others have investigated the influence of the impedance mistnatch of the binder and the explosive to the sensitivity. Schrader et al. have shown that the decomposition of the polymer followed with catalytic decomposition of the explosive can increase the sensitivity of AP-based rocket propellants [10].

The above shows that there is a large range of interest from the fundamental level of understanding for the explosive molecule until the application of a PBX in a warhead or as a booster. In all stages we have to understand the nature of the sensitivity of explosive. At TNO-PML we are trying to understand and control the sensitivity of RDX-based PBX's by controlling the quality of the RDX crystals. In that way we try to understand the role of the crystal size, crystal defects and imperfections, crystal interaction with the binder and with other crystals, etc. However it seems that each question being solved generates more new questions. In the following chapters a series of examples is given on different factors effecting the sensitivity of explosives.

\section{EXPLOSIVE AND TEST METHOD}

Most experiments are carried out on cast-cured HTPB-based PBX's with RDX as a high explosive. The solid loading of the PBX varies depending on the use of monomodal $(65 \%)$ or bimodal $(85 \%) \mathrm{RDX}$. Standard procedures and binders are used to cast-cure the PBX [6].

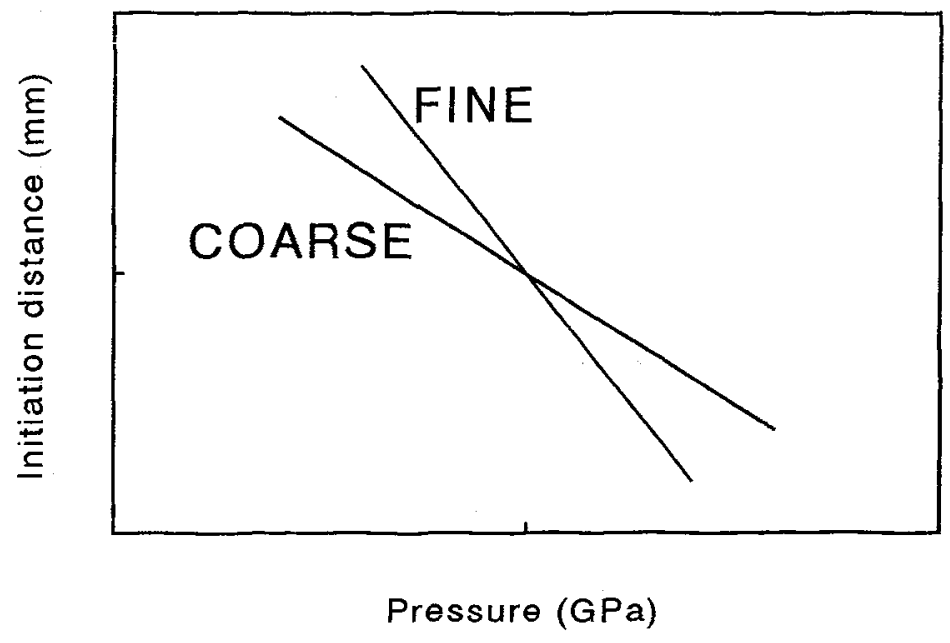

Figure 1: Schematic representation of the initiation distance of an explosive consisting of coarse or fine crystals, as a function of the initiation pressure. 
The shock sensitivity of the PBX's is determined with a gap test [6]. It has a diameter of $50 \mathrm{~mm}$, hexocire as a donor explosive (an RDX-wax composition) and a PMMA gap. Using an optical streak camera the distance between the PMMA-acceptor interface and the place the detonation wave emerges from the outer surface of the charge is measured. This initiation distance is slightly different as measured on the central axis of the set-up but this test method allows fast experiments. The initiation distance is measured as a function of the shock pressure in the PMMA at the PMMA-explosive interface. The initiation distance is considered to be a good description of the shock sensitivity of the charge.

\section{MONOMODAL RDX}

Generally it is accepted that the critical initiation pressure becomes higher if the crystal size decreases. Schematically this is illustrated in Figure 1 . It is assumed that at relatively low pressures the composition with the coarser crystals is more sensitive (gives shorter initiation distances) because those crystals are more easily ignited than the finer crystal. In other words the ignition process is the controlling step. At higher pressures the growth of the reaction is controlling and the larger surface area of finer crystals causes a higher sensitivity. This crossing of the sensitivity as a function of the initiation pressure has been found by several investigators. Table 1 lists the particle sizes of four batches of RDX with different crystal sizes (two coarse and two fine batches).

Table 1: Average crystal size (50\%), 10\% and $90 \%$ limits of the crystal size distribution and specific surface of two fine and two coarse RDX batches.

\begin{tabular}{|lccc|}
\hline F1 & $\begin{array}{c}50 \% \\
\mu \mathrm{m}\end{array}$ & $\begin{array}{c}10 \%-90 \% \\
\mu \mathrm{m}\end{array}$ & $\begin{array}{c}\text { Specific surface } \\
\mathrm{m}^{2} / \mathrm{cm}^{3}\end{array}$ \\
\hline F2 & 4.7 & $2.2-10.7$ & 1.65 \\
\hline $\mathrm{C} 1$ & 47 & $27-73$ & 0.1567 \\
\hline $\mathrm{C} 2$ & 234 & $177-315$ & 0.0305 \\
\hline
\end{tabular}

In Figure 2 the initiation distances for four PBX's with a solid loading of $65 \%$ RDX are given as a function of the initiation pressure. No crossing of the sensitivities is observed at higher pressures. The largest crystals (C2) are not the most sensitive but the sensitivity lies in between the sensitivitv of the $\mathrm{F} 2$ and $\mathrm{C} 1$ crystals.

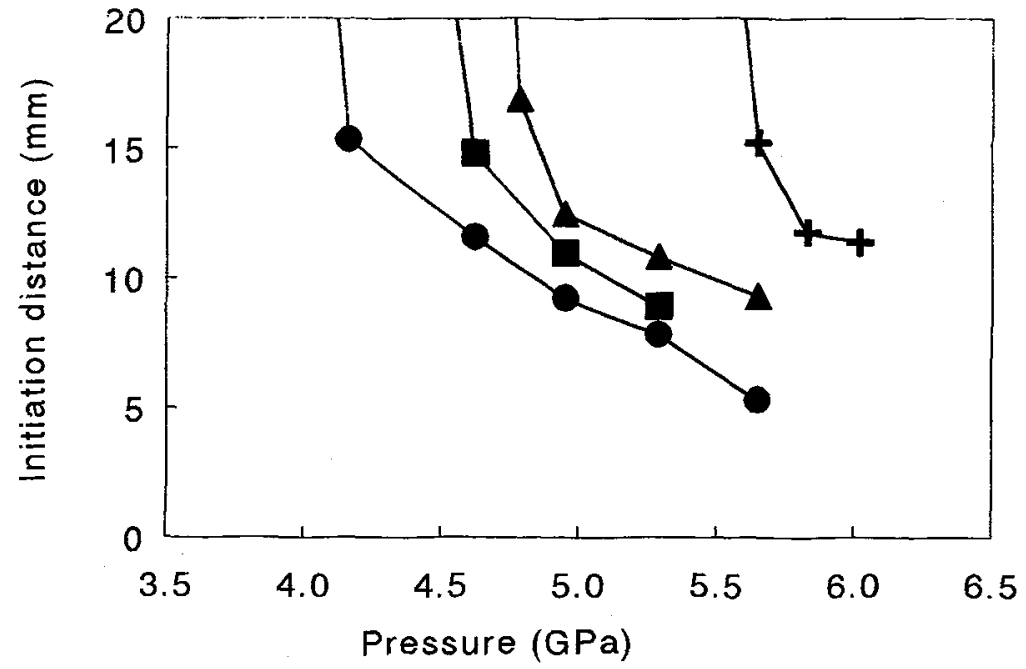

Figure 2 Initiation distances as a function of the initiation pressure for four PBX's with different RDX crystals, see Table $\mathrm{I} \cdot=\mathrm{C} 1, \mathbf{\nabla}=\mathrm{C} 2, \boldsymbol{\Delta}=\mathrm{F} 2$ and $+=\mathrm{F} 1$. 
Crossing of the sensitivities is observed when the initiation distances are determined with a so-called electric gun. In that case the explosives are initiated by the impact of a thin kapton flyer. For thin flyers the rare-faction waves extinguish the shock waves and therefore much higher pressures are needed to initiate the explosive. Two different thicknesses of flyers $(125 \mu \mathrm{m}$ and $250 \mu \mathrm{m})$ are used and the thicker the flyer the more the shock wave will resemble the initiation wave for the gap test. Results are presented schematically in Figure 3. Contrary to the gap test the coarse crystals are the most sensitive for a flyer thickness of $125 \mu \mathrm{m}$. The critical pressure for the fine is about $21 \mathrm{GPa}$ and for the coarse $15 \mathrm{GPa}$. For a flyer of $250 \mu \mathrm{m}$ these critical pressures lie much closer together although the fine is still the most sensitive ( 10 and $12 \mathrm{GPa}$ ). As has been observed already in Figure 2 the situation is reversed for the gap test experiments although the difference is still very small (about 4 and $6 \mathrm{GPa}$ ). More details can be found in reference [11].

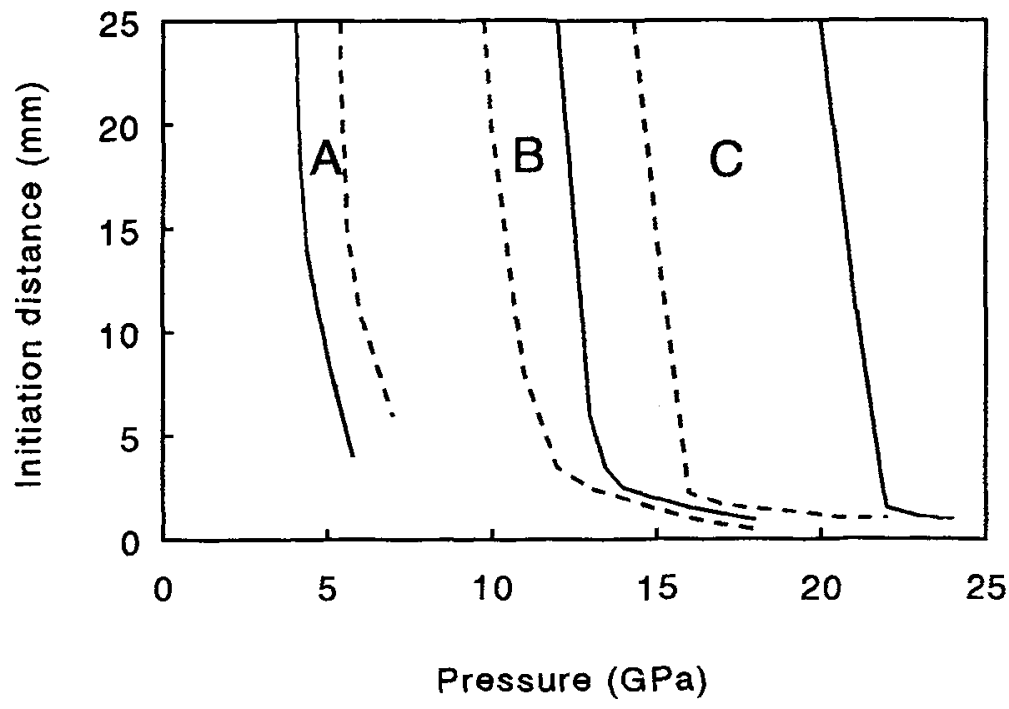

Figure 3: Schematic representation of the initiation distances as a function of the initiation pressure for PBX's with fine (--) and coarse (-) RDX for three different impulses. A: gap test, B: flyer $250 \mu \mathrm{m}, \mathrm{C}$ : flyer $125 \mu \mathrm{m}$.

These results for monomodal RDX indicate that in general the model of Figure 1 holds for the sensitivity of explosives. Deviations occur as is demonstrated in Figure 2 and can be found in [11]. Also the length of the pressure pulse has to be taken into account. The influence of the solid loading, all presented experiments have a solid loading of $65 \%$, on the shock initiation process has to be clarified further. It seems that the application of different thicknesses of flyers in the electric gun offers a very simple and fast technique to study the initiation of explosives as a function of the length (impulse) of the shock wave.

\section{BIMODAL RDX}

Bimodal mixtures of RDX are applied to increase the amount of high explosive in the PBX. To explain the sensitivity for bimodal mixtures becomes however more complicated. Important parameters are - again the crystal sizes and the ratio of the coarse and fine fraction applied.

In Figure 4 the sensitivities of two PBX's with bimodal RDX are compared. The coarse fraction has in both cases the same diameter $(370 \mu \mathrm{m})$. The fine fraction is about $20 \mu \mathrm{m}$ for one sample and $55 \mu \mathrm{m}$ for the other. The coarse fine ratio is $64 / 36$. It shows that the PBX with the smallest crystals has a critical pressure that is about $0.5 \mathrm{GPa}$ lower than for the larger crystals. 


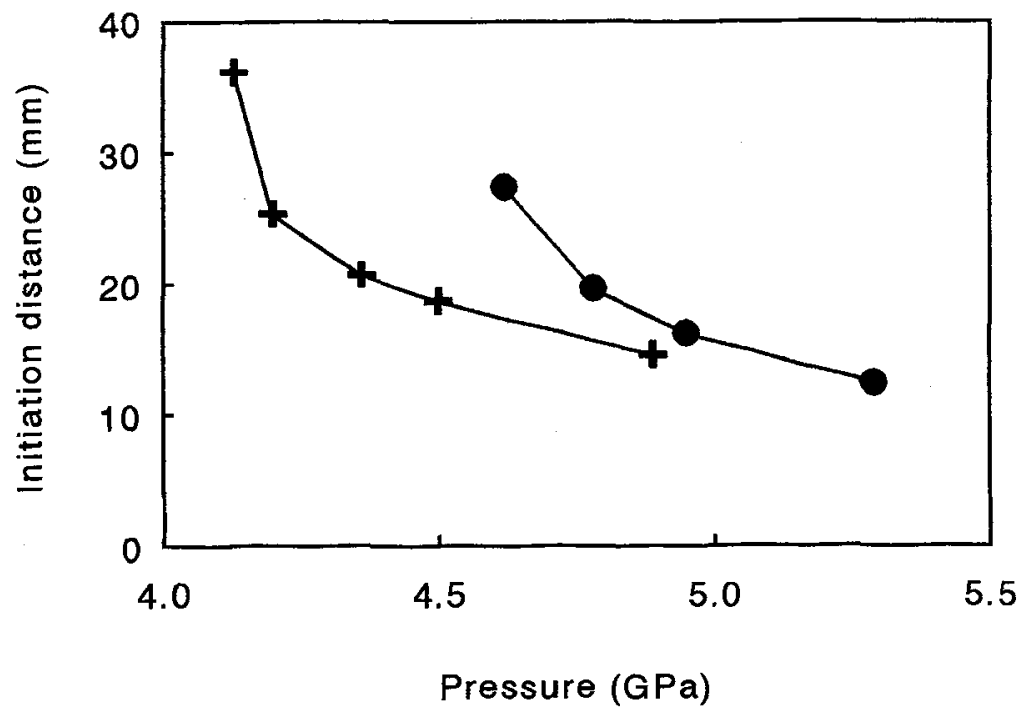

Figure 4 : initiation distances as a function of the initiation pressure for a PBX with a fine fraction of $20 \mu \mathrm{m}$ $(+)$ and a fine fraction of $55 \mu \mathrm{m}(\mathbf{)})$. The coarse fraction is the same for both RDX's.

The same is observed by varying the ratio coarse/fine in the PBX. The results for three coarse/fine ratio's are shown in Figure 5. In this case also the PBX with the largest amount of fine crystals is the most sensitive

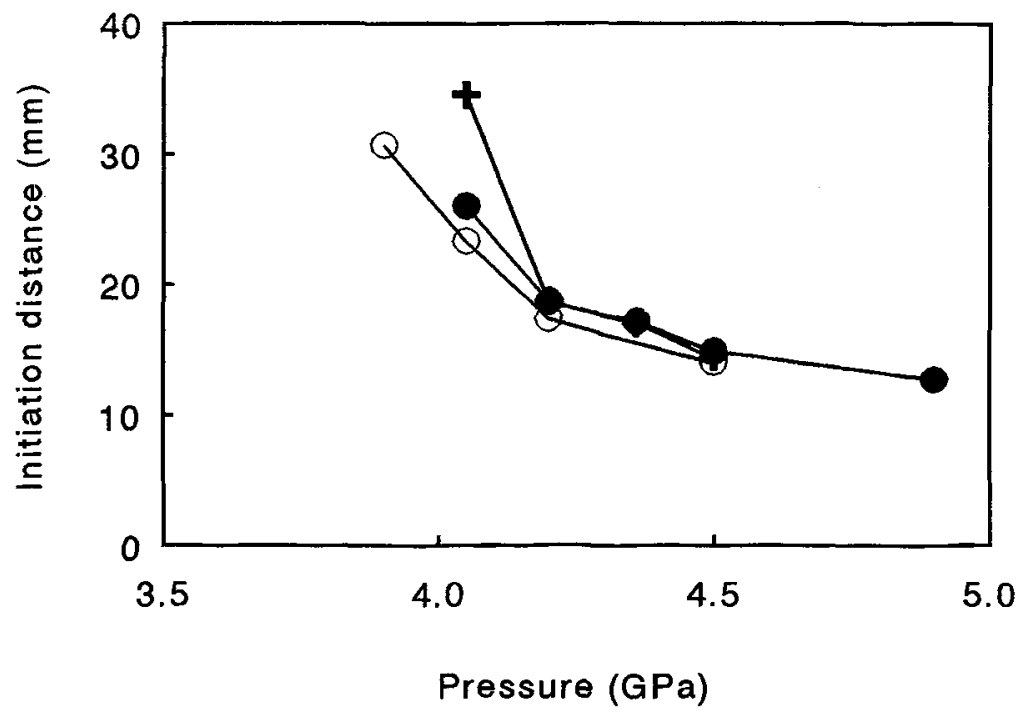

Figure 5 - Initiation distance as a function of initiation pressure for PBX's with different ratio's of coarse and fine RDX. O) $\mathrm{C} / \mathrm{F}=59 / 41,0) \mathrm{C} / \mathrm{F}=64 / 36,+) \mathrm{C} / \mathrm{F}=76 / 24$.

Both observations seem to be contradictory to the model shown in Figure 1. It assumes that (at relatively low pressures, and that is the case in these examples) the smaller the crystals the less sensitive is the explosive. The reversal in the bimodal samples is caused by the presence of the coarse crystals. If fine and coarse crystals are both present in a PBX it is most likely that the coarse crystal will be ignited at the lowest (critical) pressures. The subsequent build-up to a detonation reaction will be determined by the specific surface of the RDX. Since this is considerably higher for the fine crystals it is not unexpected that 
the increase of the amount of fine crystals or the decrease of the crystal size of the fine fraction increases the sensitivity of the PBX.

These results are only qualitatively and many questions remain. For example it is not yet clear how the distance between the coarse and the fine crystals effects the initiation process (how is the energy transfer) Also it is not evident how much of a coarse fraction is needed to ignite the decomposition reaction. And last but certainly not least: why are the coarse crystals the most sensitive?

\section{MODELLING}

There are many models available to simulate the shock initiation of explosives. The most well known are the Forest Fire and the Lee-Tarver model. The Forest Fire model is very crude and empirical and cannot be applied to parameter studies as are presented above. The model is more suitable for simulating the shock initiation behaviour of different explosives.

The Lee Tarver model is also referred to as the ignition and growth model and is founded on the knowledge that the shock initiation in heterogeneous explosives is based on the formation and subsequent reaction of the hot spots that are created when the shock pulses compresses the solid. In the model one ignition term and two growth terms are applied. The ignition and growth terms can help to understand qualitatively the shock initiation process. They could be an indication for the number of defect where ignition starts and how easily a reaction grows to completion. A disadvantage of the model is that it can only simulate one (spherical) particle size. Bimodal mixtures (two crystal sizes) cannot be simulated. The transfer of the ignition reaction from the coarse crystals to the fine crystals is not yet understood.

The simulation of monomodal explosives gives some interesting result [12]. In these simulations the initiation distance was calculated as a function of the initiation pressure. In Figures 6 the results are given for a variation of the amplitude of the first grovi in term (G1) and the ignition term (I).
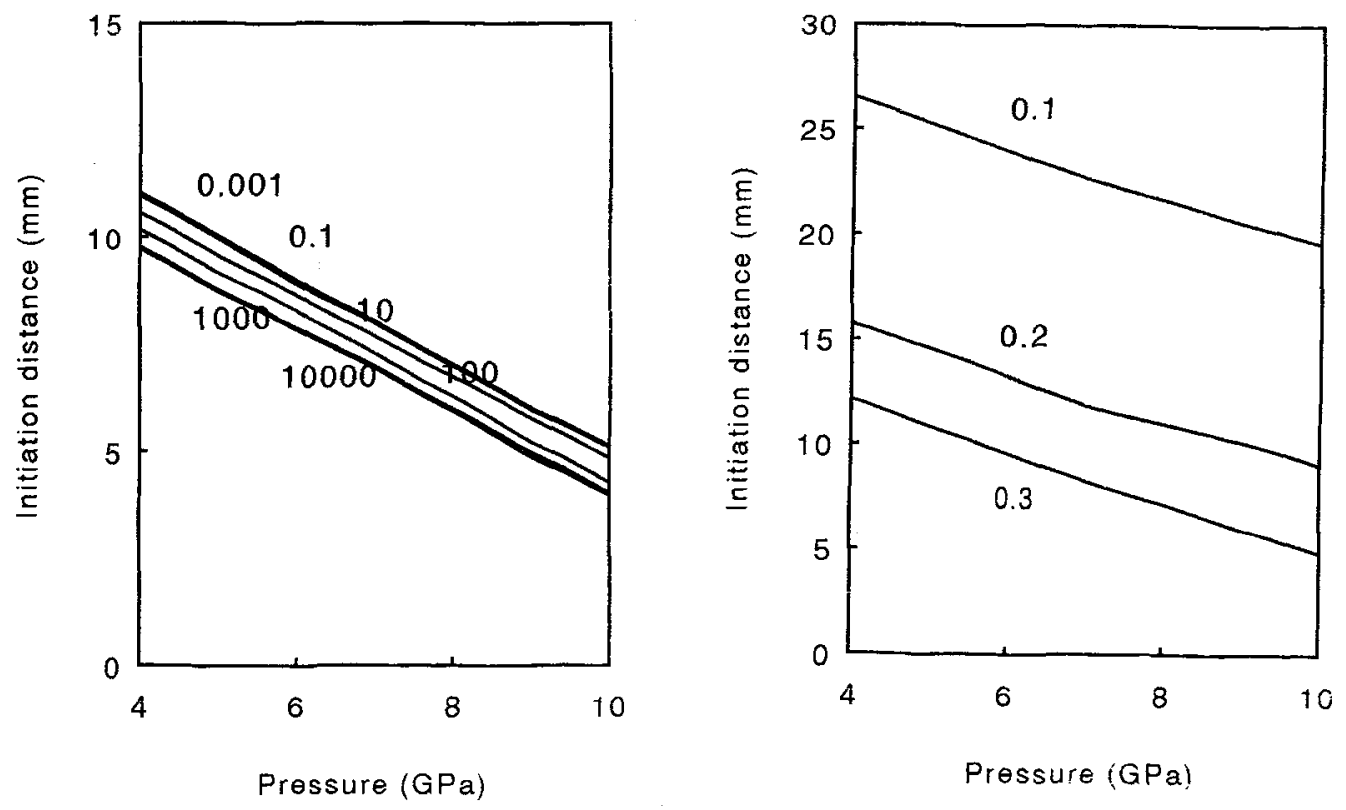

Figure 6: The simulated initiation distance as a function of the initiation pressure for different values of the ignition term (left) and the growth term (right) in the iee-Tarver model. 

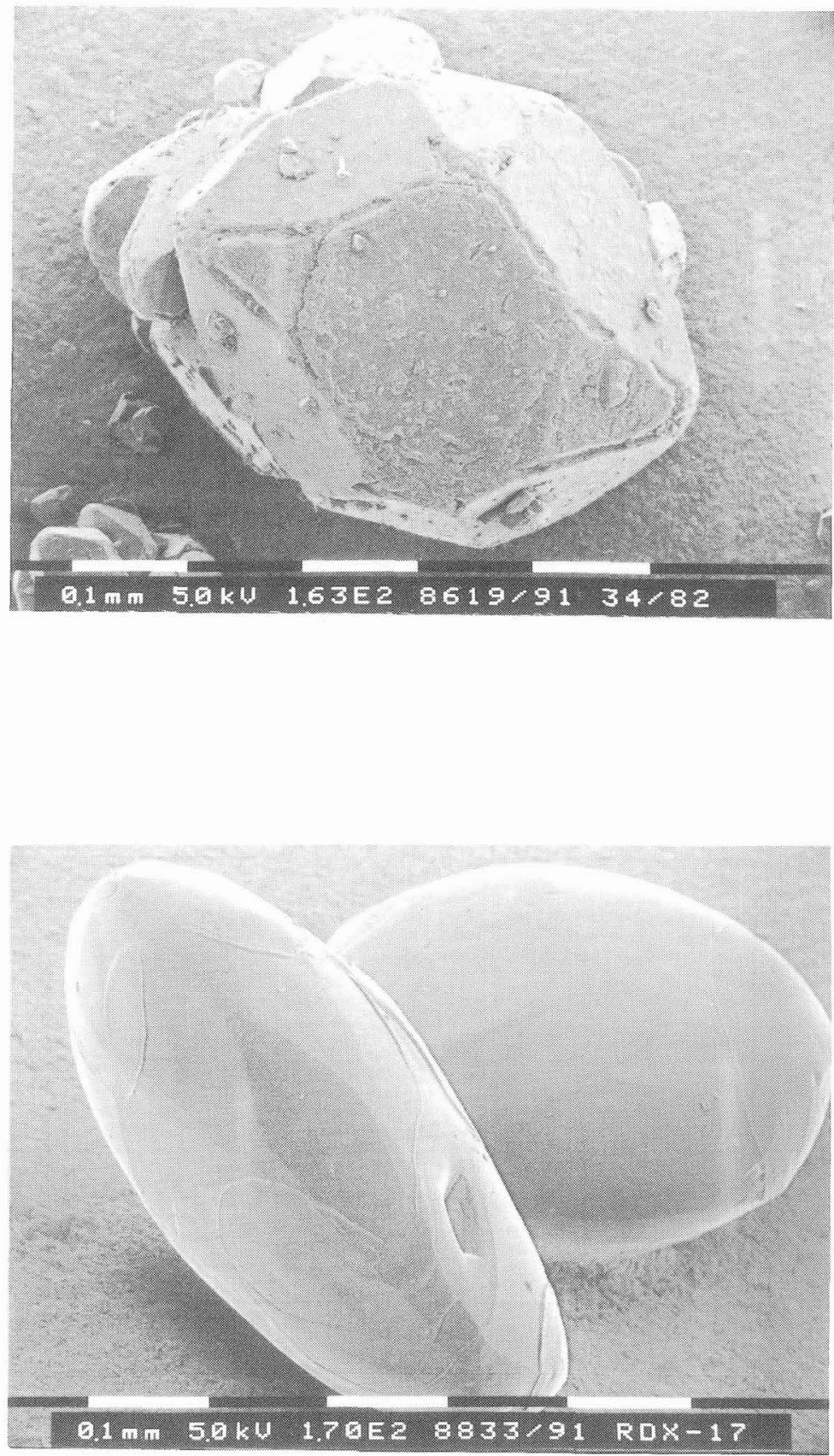

Figure 7: Scanning Electron Micrographs of a typical RDX crystal (top) and a crystal that has been posttreated (bottom) to obtain a better morphology. 
These results show that the growth terms dominate the initiation process. A variation of 0.05 to 0.3 in the growth term results in a much larger variation in the initiation distances than a variation of $10^{+7}$ in the ignition term. This seems to be in accordance with the findings for the bimodal mixtures. For those mixtures it is also found that small variations in the fine material (growth) causes large variations in the sensitivity. On the other hand, these simulations do not explain the results for the monomodal PBX's. Considering the simulations the ignition term plays a minor role and the crossing of the sensitivity curves cannot be explained.

\section{CRYSTAL QUALITY}

All results presented above are interpreted with respect to the crystal size and the crystal size distribution while the crystals are assumed to be spheres. Unfortunately crystals seldom have the shape of a sphere. This is illustrated in Figure 7 where two Scanning Electron Micrographs (SEM) are given of RDX crystals. Both have about the same diameter. One has the typical structure of an RDX crystal as obtained directly from the recrystallization vessel. The faces of the crystal can be assigned to the different growth directions of the crystal. The other crystal is more oval shaped and has a very smooth surface. This crystal has been post-treated with the solvent ethyl acetate. Its morphology is much more regular and can be defined with only two parameters.

The influence of the morphology of the crystals on the shock sensitivity is shown in Figure 8. PBX's with the same fine fraction $(47 \mu \mathrm{m})$ but with an angular and not post-treated coarse fraction and a coarse fraction that has been post-treated are compared. The diameter of the coarse fraction is $480 \mu \mathrm{m}$ before the post-treatment and $450 \mu \mathrm{m}$ afterwards. It shows that especially at the initiation threshold the PBX with the smoother crystal is about $0.4 \mathrm{GPa}$ less sensitive than the angular crystals. The differences are less pronounced for the higher pressures. Unfortunately the sensitivity for monomodal PBX's has not (yet) been measured.

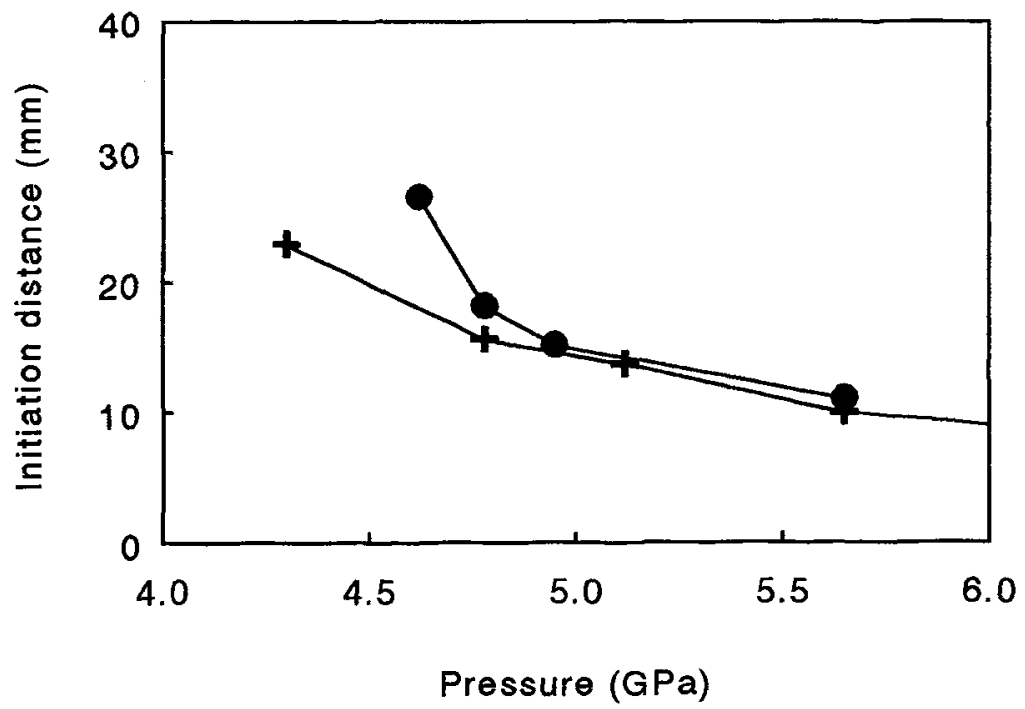

Figure 8: Initiation distances as a function of initiation pressure for a PBX with + ) angular crystals and $)$ oval shaped crystals as the coarse fraction.

These results show that not only the particle size plays a role in the sensitivity but also the morphology of the crystals. There are several possible explanations for the decreased sensitivity: 


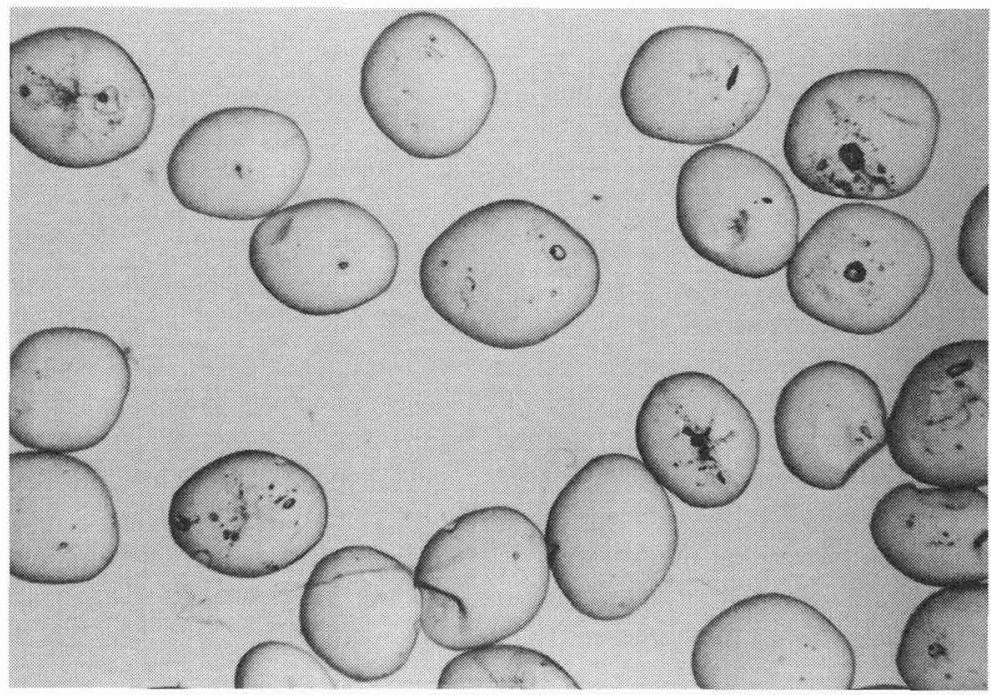

Figure 9: Light microscopy of RDX crystals. Empty and filled voids are visible.

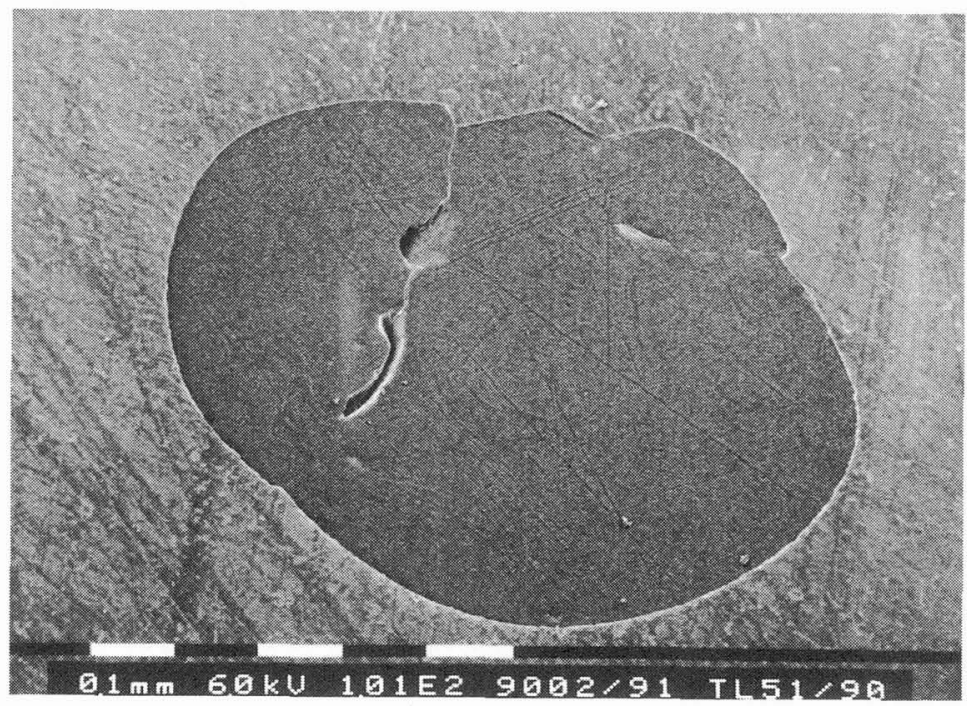

Figure 10: SEM picture of a cross section of an RDX crystal. A void and different crystals orientations are visible. 
- The tap density with the spheroidized particles is higher. The increased average distance between the crystals could cause the decreased sensitivity.

- A better contact between the binder and the crystal is possible for smoother crystals, voids could still be present at the interface for the angular crystals and cause ignition.

- Angular crystals are more sensitive than speroidized crystals because ignition occurs at the corners of the crystals.

The morphology tells something about the "outside" of the crystals. Figure 9 shows the "inside" of RDX crystals as can be seen with a light microscope. Voids, sometimes filled with solvent, of all different sizes and shapes can be observed. In Figure 10 a cross section is given of one crystal. An elongated void that was probably filled with the solvent is clearly visible. All these imperfections are caused by the crystallisation process. Depending on the type of crystallisation (cooling, evaporation, etc.) and the growing rate the internal and external quality of the crystal will be influenced. Borne has already indicated that crystals with a higher density, and therefore a smaller number of voids, have a lower initiation threshold [7]. Also Chan has shown that the sensitivity of CL20 can be less by improving the crystallisation method [13]. It is assumed that these voids act as ignition sites. Void collapse, adiabatic heating, plastic flow, etc. are generally considered as the processes to form hot-spots.

Cutting crystals and etching the surfaces yields even more information as can be seen in Figure 11 . The different growth directions and the interfaces in between are clearly visible. It can not be excluded that at these interfaces with a relatively high number of dislocations a pile-up of energy occurs as has been described by Coffey and Armstrong [2]. Crystallisation studies and detailed techniques to follow the initiation (or better the ignition and growth) processes have to reveal these questions in the future.

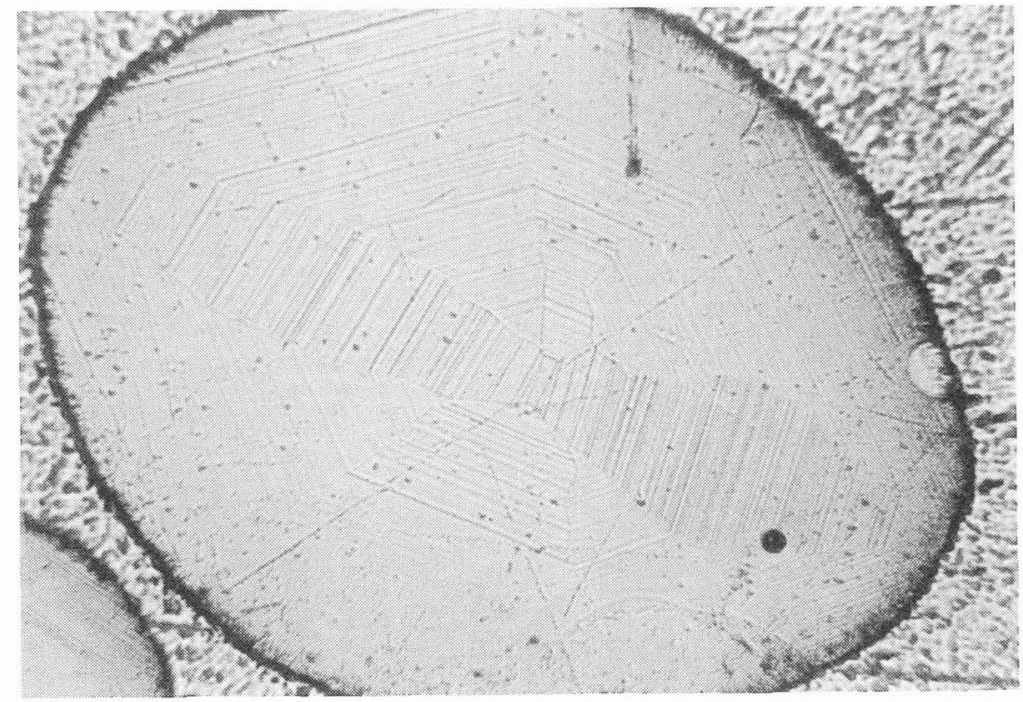

Figure 11: Cross section of an RDX crystal. The growth sectors and a seed crystal in the centre are clearly visible.

\section{CONCLUSIONS}

Most of the time fundamental studies on sensitivity refer to ideal systems as one molecule or a single crystal. It is impossible to detonate a molecule and from the studies of Dick on PETN [14] we know that it is very hard to detonate a crystal. Recently at Lawrence Livermore National Laboratory it has been shown that initiation in single crystals only occurs after the shock wave has reflected against an interface. 
This paper has tried to give some more insight in physical parameters affecting the sensitivity. The results are mainly qualitative and still many questions remain. The most important are:

- How are (coarse) crystals ignited?

- How does the energy transfer between crystals take place?

- How far can we decrease the sensitivity of an RDX based PBX by optimising the crystal quality?

It is this last question that is the most important. Crystallisation of RDX is getting more attention in the detonation community at the moment and hopefully there will be a few answers in the coming years.

\section{Acknowledgements}

The research project was carried out under assignment A93KL447 for the Royal Dutch Army. The author would like to thank all his colleagues who contributed to this work: Willem Duvalois, Aat Hordijk, Antoine van der Heijden, Wim Prinse, Murk van Rooijen, Benoit Coleau, Jos Mul, Rene Oostdam, Ries Verbeek en Ed de Jong.

\section{References}

1. A. Delpuech, Initiation des explosifs à l'échelle moléculaire, Approches Microscopique et Macroscopique des Détonations (Les éditions de Physique, Megève, 1987), 353 (1987)

A.E. Delpuech, The use of time-resolved spectrometries in the study of initiation of explosives at molecular level, Proceedings Ninth Symposium (International) on Detonation, Portland, 172 (1989) S. Odiot, Mechanisms of detonation in molecular crystals: a review, Approches Microscopique et Macroscopique des Détonations (Les éditions de Physique, Megève, 1987), 225 (1987)

S. Odiot and M. Peyrard, Why does an explosive explode?, Approches Microscopique et Macroscopique des Détonations (Les éditions de Physique, Megève, 1987), 393 (1987)

2. C.S. Coffey, Energy localization and the initiation and detonation of crystalline explosives by shock or impact, Proceedings Workshop Desensitization of Explosives and Propellants, TNO Prins Maurits Laboratory, Rijswijk, The Netherlands, November 1991

R.W. Armstrong, Dislocation mechanics aspects of desensitization to impact or shock deformations, Proceedings Workshop Desensitization of Explosives and Propellants, TNO Prins Maurits Laboratory, Rijswijk, The Netherlands, November 1991

C.S. Coffey and R.W Armstrong, This workshop

3. H. Moulard, J.W. Kury and A Declos, The effect of RDX particle size on the shock sensitivity of cast PBX formulations, Proceedings Eight Symposium (International) on Detonation, Albuquerque, 902 (1985)

H. Moulard, Particular aspects of the explosive particle size effect on shock sensitivity of cast PBX formulations, Proceedings Ninth Symposium (International) on Detonation, Portland, 18 (1989)

4. R.J. Spear and V. Nanut, Mechanism of and particle size effects on shock sensitivity of heterogeneous pressed explosives: preliminary assessment of binderless RDX in fuze trains, DOD Materials Research Laboratories, Melbourne Australia, MRL-R-1077 (1987)

5. I.B. Mishra and L.J. Vande Kieft, Novel approach to insensitive explosives, 19th International Annual Conference of ICT 1988, Karlsruhe, 25-1 (1988)

6. A.C. van der Steen, H.J. Verbeek and J.J. Meulenbrugge, Influence of RDX crystal shape on the shock sensitivity of PBXes, Proceedings Ninth Symposium (International) on Detonation, Portland, 83 (1989)

A.C. van der Steen and E. Skjold, RDX particle shape and the sensitivity of PBXes, 1990 Joint Government/Industry Symposium on Insensitive Munitions Technology (Addendum Proceedings), White Oak, 235 (1990) 
A.C. van der Steen, E.G. de Jong, W.C. Prinse, A.C. Hordijk and W Duvalois, Crystal quality and shock sensitivity of RDX-based PBXes, Tenth Symposium (International) on Detonation, Boston, (1993) to be published

7. L. Borne, Influence of intragranular cavities of RDX particle batches on the sensitivity of cast plastic bonded explosives, Proceedings Tenth Symposium (international) on Detonation, Boston, (1993) to be published

8. G.M. Swallone and J. Field, Proc. R. Soc. Lond. A., Vol. 379, 389 (1982)

9. F. Schedlbauer and A. Kretschmer, The influence of particle size and mechanical properties on the sensitivity of high explosive charges (PBX), Proceedings Tenth Symposium (International) on Detonation, Boston, (1993) to be published

10. M.A. Schrader, M.W. Leeuw and A.C. van der Steen, The heat sensitivity of solid propellants, AGARD Conference Proceedings No. 367, Hazard studies for solid rocket motors, Lisse, 19 (1984)

11. W. Prinse, M. van Rooijen, B. Coleau, J. Mul, R. Verbeek and A. van der Steen, Shock sensitivity testing of explosives with the gap test and thin flyer impact test, Europyro 1995, to be published

12. R. Verbeek and A. van der Steen, The simulation of shock initiation of less sensitive explosives using the hydrocode autodyn, Proceedings Tenth Symposium (international) on Detonation, Boston, (1993) to be published

13. M. Chan, NAWC, China Lake, Private communications

14. J. Dick, This workshop 